\title{
Clinical Evaluation of Removable Partial Dentures on the Periodontal Health of Abutment Teeth: A Retrospective Study
}

\author{
Linda J. Dula ${ }^{1, \#, *}$, Enis F. Ahmedi ${ }^{1,2, \#}$, Zana D. Lila-Krasniqi ${ }^{1, \#}$ and Kujtim Sh Shala, ${ }^{1, \#}$ \\ ${ }^{I}$ Department of Prosthetic Dentistry, Faculty of Medicine, School of Dentistry, Prishtina, Kosovo; ${ }^{2}$ MedUni Graz, \\ Dental School, Graz, Austria
}

\begin{abstract}
The aim of this retrospective study was to evaluate the effect of removable partial dentures in periodontal abutment teeth in relation to the type of denture support and design of RPD in a five-year worn period. Methods: A total of 64 patients with removable partial dentures (RPDs), participated in this study. It were examined ninety-one RPDs. There were seventy-five RPDs with clasp-retained and sixteenth were RPDs with attachments. There were 28 females and 36 males, aged between 40-64 years, 41 maxillary and 50 mandible RPDs. For each subjects the following data were collected: denture design, denture support, and Kennedy classification. Abutment teeth were assessed for plaque index (PI), calculus index (CI), blending on probing (BOP), probing depth (PD), gingival recession (GR), tooth mobility (TM). Level of significance was set at $\mathrm{p}<0.05$. Results: According to denture support of RPD, BOP, PD, PI, GR, CI and TM-index showed no statistically significant difference. Based on the denture design of RPD's, BOP, PD, PI, CI, and TM-index proved no statistically significant difference. Except GR-index according to denture design confirmed statistically significant difference in RPD with clasp $\mathrm{p}<0.01$. The higher values of all periodontal parameter as BOP, PD, PI, CI and TM were in patients with RPD's with claps comparing with RPD's with attachment. Conclusion: RPD's with clasp increased level of gingival inflammation in regions covered by the dentures and below the clasp arms in abutment teeth.
\end{abstract}

Keywords: Abutment teeth, periodontal health, removable partial denture (RPD).

\section{INTRODUCTION}

Removable partial denture therapy (RPD) is an adequate form of treatment for patients with missing teeth. In these circumstances RPDs represent an acceptable and economical modality treatment for patients with partial edentulous [1].

McCracken proposes biomechanics principles for design of RPD's, which focuses on the distribution of forces in the supporting tissues by providing retention and stability of the RPD [2]. Further, Marxkors paid attention that principles design for RPD was controlling dental plaque for the prevention of caries and periodontal disease, known as hygienic design principles where the marginal gingival is free [3].

Epidemiological studies in animals and in humans have shown that dental plaque is an essential factor in the ethology of periodontitis. If plaque control was established, gingivitis and periodontitis can be satisfactorily treated [4]. The RPD in the mouth has the potential for increase plaque formation on tooth, especially to abutment teeth, to which clasps or attachments are attached [5-8]. The RPD framework designs contribute in increasing oral bacterial flora and formation of dental plaque. Kennedy classification, denture base shape, denture construction and especially the number of position of the clasps and occlusal rests also influence periodontal deterioration [9].

*Address correspondence to this author at the Department of Prosthetic Dentistry, Faculty of Medicine, School of Dentistry, Prishtina, Kosovo;

Tel: +381 38512 525; Fax: +381 38512 474;

E-mail: drlindadula@gmail.com

\#These authors contributed equally to this work
The main reason for the failure of RPD is the loss of abutment teeth due to periodontal changes and caries [10]. Longitudinal studies of RPDs manifested with gingivitis, periodontitis and mobility of abutment teeth [11]. RPDs can increase the incidence of caries; damage the periodontium, relatively large amounts of plaque and the amount of stress on natural teeth [12-17]. These changes occur due to poor oral hygiene, increased plaque and calculus accumulation [18].

Therefore the control of dental plaque is important to obtain good denture prognosis and performance for a long period. Many studies have investigated the effect of regular checkups on oral health and denture hygiene with carefully planned prosthetic treatment. All periodontal parameters appeared with better results in patients who were going to receive RPDs and they should be carefully motivated and instructed in order to prevent periodontal diseases [14, 19].

The aim of this retrospective study was to evaluate the effect of removable partial dentures in periodontal abutment teeth in relation to the type of denture support and design of RPD in a five-year worn period. The defined recordings of plaque index (PI), calculus index (CI), blending on probing (BOP), probing depth (PD), gingival recession (GR), tooth mobility (TM) were measured on abutment teeth and analyzed due to design and denture support of RPDs.

\section{MATERIALS AND METHODOLOGY}

The research has been accepted and approved by the Institutional Ethic Committee (School of Dental Medicine, 
University of Prishtina) and a written consent was obtained from each subject.

A total of 64 patients with RPD made by different clinicians at the Prosthodontics Department at University Dentistry Clinical Center, in Prishtina, Kosova, were contacted by phone and they have been invited to participate in this study. The patients were chosen by consecutive form, from the prosthetic delivery files of the department. They were wearing existing RPDs for different periods, from one to five years after placement.

The measurements were done by a single examiner to reduce interobserver error, and each measure was taken for three times and the average of three values was obtained to minimize the intraobserver error. For each subject the following data were collected:

- Denture design for each individual patient was based on the state of the remaining teeth and the status of their oral health. There were the RPD's with clasp-retained with extracoronal direct and indirect retainers and the RPD's with attachment retained. The framework casts were made by cobalt-chrome-molbiden alloys ( $\mathrm{Co}-\mathrm{Cr}-\mathrm{Mo})$.

- The classification for partially edentulous was made by Kennedy 1925, denoted Class I through Class IV [20].

- According to Steffel 1962 denture support of the RPDs was classified point, linear, triangular, quadrangular design. Linear support was divided into diametric, diagonal and transversal [21].

Abutment teeth used as direct or indirect retainer for the RPD, periodontal examination was conducted and the following variables were determined: plaque index (Silness/Löe), calculus index (Green-Vermilion), bleeding on probing (BOP), probing depth (PD), gingival recession (GR) and tooth mobility (TM).

- Plaque index (PI) according to Silness/Löe Index 1964 [22].

- Calculus index (CI), according to Green-Vermilion Index 1964 [23].

- Bleeding on probing (BOP) according to Ainamo \& Bay 1975 [24].

- Probing pocket depth (PD) was measured from the crest of the gingival margin to a probable pocket depth using a Williams Probe and read to the nearest millimetres $(\mathrm{mm})$. Measurements were made in the forth surfaces in abutment teeth: mesial, oral, distal and vestibular surfaces. Scores ranging from 0-3 represented the highest PD observed: 0-normal probe depth of $2 \mathrm{~mm}$ or less; 1 probe depth of about $2 \mathrm{~mm}$, but not greater than $3 \mathrm{~mm}$; 2probe depth greater than $3 \mathrm{~mm}$ but less than $5 \mathrm{~mm}$ and $3-$ probe depth greater than $5 \mathrm{~mm}$ or more [25].

- Gingival recession (GR) was measured in abutment teeth according to its presens or absence of it [26].

- Tooth mobility (TM) was recorded according to Miller 1985 from 0-3: 0-no mobility, 1-mobility smaller than 1 $\mathrm{mm}$ in the horizontal direction, 2-mobility more than 1 $\mathrm{mm}$ in the horizontal direction, 3-mobility in the apical vertical direction [27].

\section{Data Analysis}

Statistical analysis was made using Statistical Package for Social Science (SPSS) 19 for Windows (SPSS Inc., Chicago, Illinoiss, USA) and MS Excel (Microsoft Office, Windows 2007, USA). Statistical parameters were calculated from the structure index, arithmetic average and standard deviation. Testing parametric data was done with T-test and the non-parametric data with the Fisher exact test, $\mathrm{X}^{2-}$ test, Mann-Whitney test and Kruskal Wallis test. Difference in $\mathrm{p}<0.05$ were considered significant.

\section{RESULTS}

\section{Study Population and Dentures Characteristics}

The 64 patients with removable partial dentures participated in this study. There were 28 females and 36 males, aged between 40-64 years (Table 1). It was examined ninetyone RPD and each prosthesis was considered statistically independent case. There were seventy-five RPD with claspretained and sixteenth were RPD with attachments. The examined RPD were 41 maxillary arch and 50 from mandibles arch. The most frequent was RPD with linear $47.8 \%$ and triangular $22.8 \%$ denture support, and least common RPD with quadrangular $6.5 \%$ and one point $4.3 \%$ denture support (Table 2). More than half of partially edentulous was Kennedy I and I with modification, $11 \%$ class II, IIA $13.2 \%$ and $4.4 \%$ IIB, Class III and IV have a small percentage (Table 3).

\section{Clinical Periodontal Parameters}

According to denture support of RPD's, BOP-index (Table 4), PD-index (Table 5), PI-index (Table 6), GR-index (Table 7), CI- index (Table 8) and TM-index (Table 9), showed no statistically significant difference. Therefore, the values of all periodontal parameter as BOP, PD, PI, CI, GR and TM were high between dental support of RPD, but no significant difference between them, because of the small number of patients with quadrangular and one point denture support of RPD.

Based on the denture design of RPD's, BOP-index (Table 10), PD-index (Table 11), PI-index (Table 12), CI-index (Table 13), and TM index (Table 14) proved no statistically significant difference. Except GR-index according to denture design confirmed statistically significant difference in RPD with clasp $\mathrm{p}<0.01$ (Table 15). However the values of all periodontal parameter as BOP, PD, PI, CI and TM were higher in patients with RPD's framework with claps retained compared with RPD's with attachment. Because of the small number of patients with RPD's with attachment the difference has not been significant and the results must be judged carefully.

\section{DISCUSSION}

A retrospective study has some disadvantages since the feature of its data is based on the feature of the clinical available records. After denture placement, every patient was advised to attend a follow-up appointment at least one in six months; nevertheless, not all patients followed this advice. 
Table 1. Comparison of gender and age.

\begin{tabular}{|c|c|c|c|c|c|c|c|}
\hline \multirow{2}{*}{\multicolumn{2}{|c|}{$\begin{array}{l}\text { Age group } \\
\text { (year) }\end{array}$}} & \multicolumn{4}{|c|}{ Gender } & \multirow{2}{*}{\multicolumn{2}{|c|}{ Total }} \\
\hline & & \multicolumn{2}{|c|}{$\mathbf{F}$} & \multicolumn{2}{|c|}{$\mathbf{M}$} & & \\
\hline \multicolumn{2}{|c|}{$<40$} & 1 & 3.6 & - & - & 1 & 1.6 \\
\hline \multicolumn{2}{|c|}{$40-64$} & 19 & 67.9 & 18 & 50.0 & 37 & 57.8 \\
\hline \multirow{2}{*}{ Total } & $\mathbf{N}$ & 28 & 100.0 & 36 & 100.0 & 64 & 100.0 \\
\hline & $\%$ & 43.8 & - & 56.3 & - & 100.0 & - \\
\hline \multicolumn{2}{|c|}{ Mean \pm SD } & \multicolumn{2}{|c|}{$57.2 \pm 10.3$} & \multicolumn{2}{|c|}{$64.5 \pm 7.7$} & \multicolumn{2}{|c|}{$61.4 \pm 9.6$} \\
\hline \multicolumn{2}{|c|}{ Rank } & \multicolumn{2}{|c|}{$34-75$} & \multicolumn{2}{|c|}{$46-79$} & \multicolumn{2}{|c|}{$34-79$} \\
\hline
\end{tabular}

Table 2. RPD Denture support according Steffel and distribution of denture $\operatorname{arch}(\mathrm{n}=91)$.

\begin{tabular}{|c|c|c|}
\hline & $\mathbf{N}$ & $\%$ \\
\hline Triangular & 21 & 22.8 \\
\hline Linear & 44 & 47.8 \\
\hline Total RPD with clasp & 75 & 81.5 \\
\hline RPD with attachments & 16 & 17.4 \\
\hline \multicolumn{3}{|l|}{ Arch } \\
\hline Maxilla & 41 & 44.6 \\
\hline
\end{tabular}

Table 3. Distribution of kennedy classification.

\begin{tabular}{|c|c|c|}
\hline Kennedy Classification & \multicolumn{2}{|c|}{ Total } \\
\hline I A & 11 & 12.1 \\
\hline I B & 3 & 3.3 \\
\hline II A & 12 & 13.2 \\
\hline II B & 4 & 4.4 \\
\hline IIIA & 1 & 1.1 \\
\hline III B & 1 & 1.1 \\
\hline Total & 91 & 100.0 \\
\hline
\end{tabular}


Table 4. Bleeding on probing (BOP) index according to denture support.

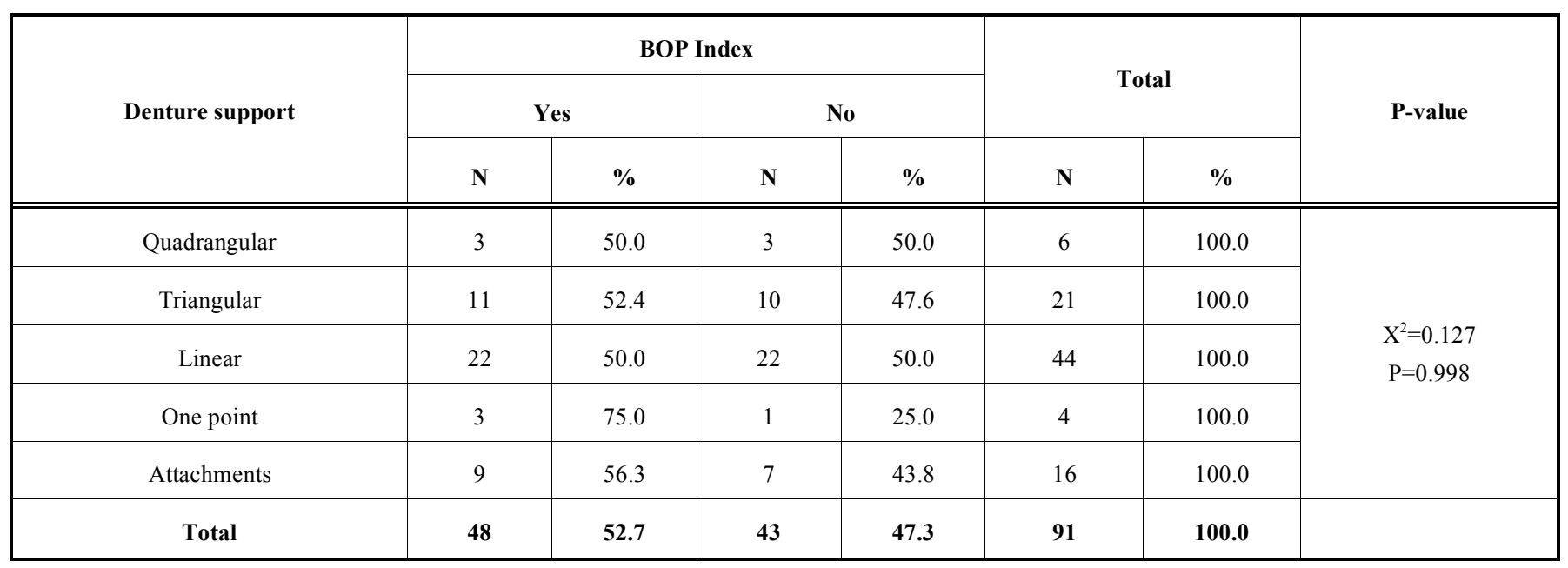

Table 5. Periodontal probing depth (PD) according to denture support.

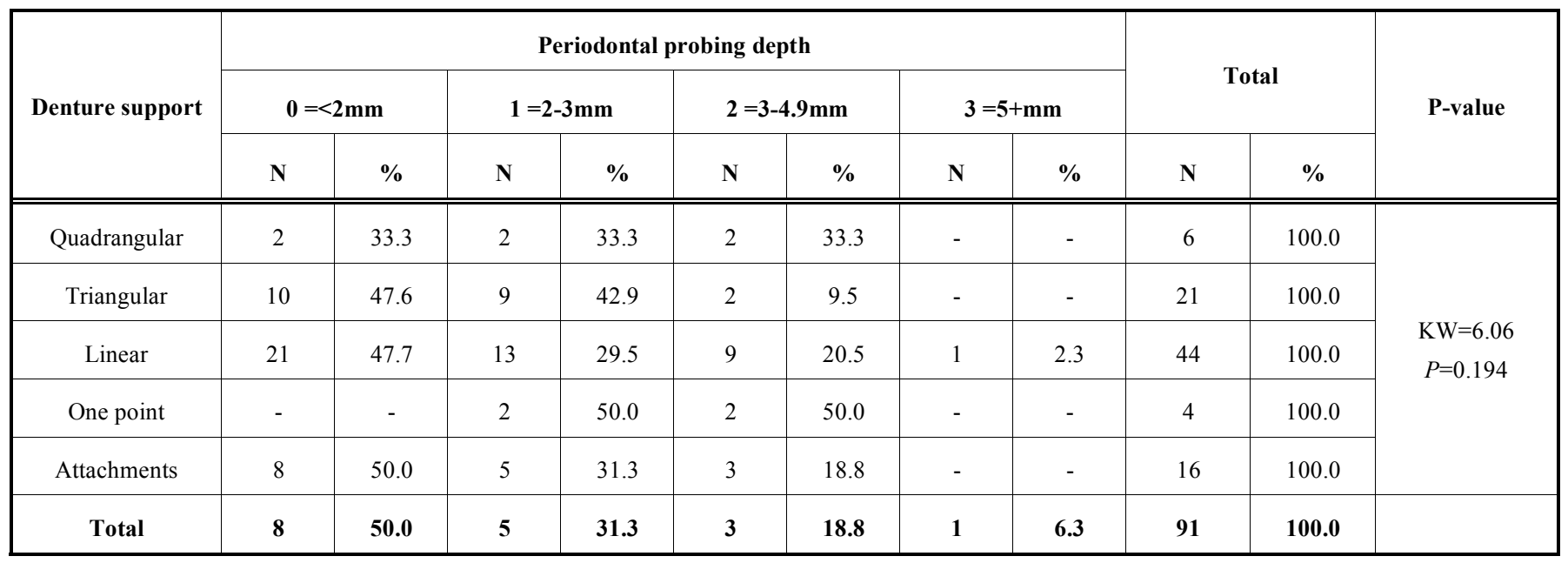

Table 6. Plaque Index (PI) based on Silness and Löe according to denture support.

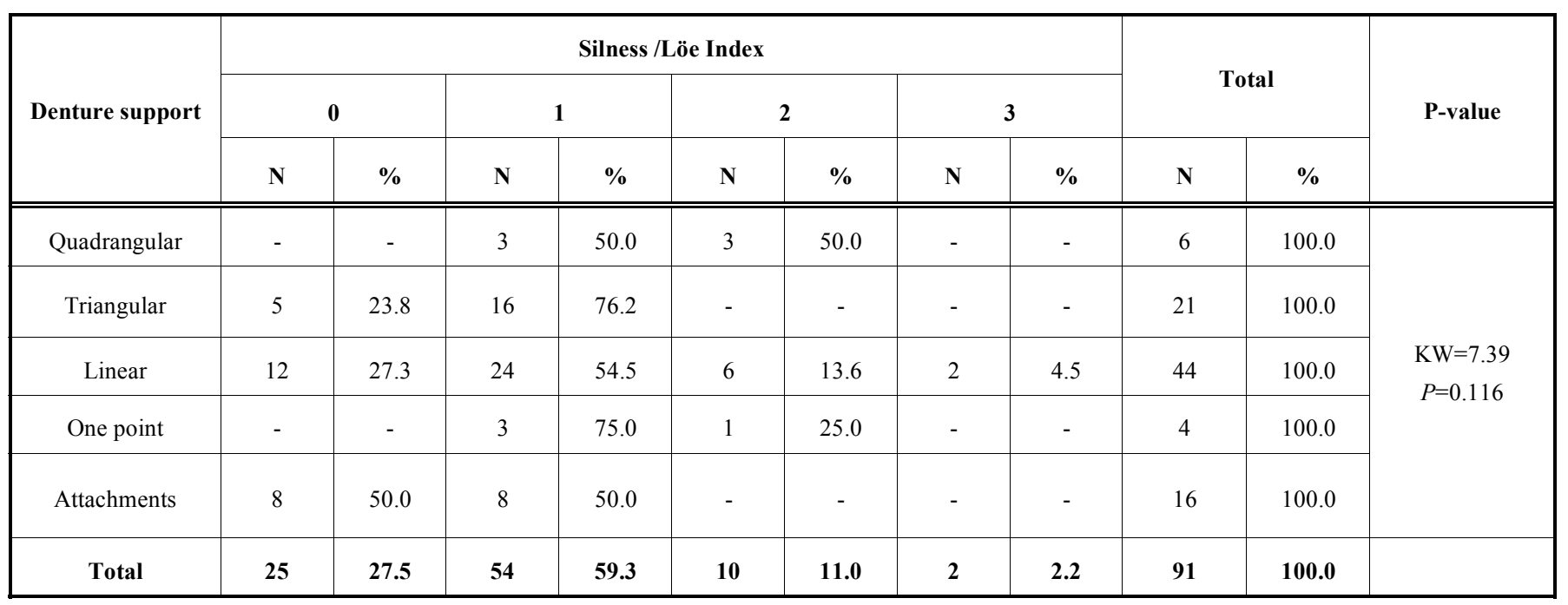


Table 7. Gingival recession (GR) index according to denture support.

\begin{tabular}{|c|c|c|c|c|c|c|c|}
\hline \multirow{3}{*}{ Denture support } & \multicolumn{4}{|c|}{ Gingival Recession } & \multirow{2}{*}{\multicolumn{2}{|c|}{ Total }} & \multirow{3}{*}{ P-value } \\
\hline & \multicolumn{2}{|c|}{ Yes } & \multicolumn{2}{|c|}{ No } & & & \\
\hline & $\mathbf{N}$ & $\%$ & $\mathbf{N}$ & $\%$ & $\mathbf{N}$ & $\%$ & \\
\hline Quadrangular & 6 & 100.0 & - & - & 6 & 100.0 & \multirow{3}{*}{$\begin{array}{c}\mathrm{X} 2=8.5 \\
P=0.07\end{array}$} \\
\hline Triangular & 16 & 76.2 & 5 & 23.8 & 21 & 100.0 & \\
\hline One point & 4 & 100.0 & - & - & 4 & 100.0 & \\
\hline Attachments & 6 & 37.5 & 10 & 62.5 & 16 & 100.0 & \\
\hline Total & 66 & 72.5 & 25 & 27.5 & 91 & 100.0 & \\
\hline
\end{tabular}

Table 8. Calculus Index (CI) based on Green-Vermilion according to denture support.

\begin{tabular}{|c|c|c|c|c|c|c|c|c|c|}
\hline \multirow{2}{*}{ Denture support } & \multicolumn{6}{|c|}{ Green Vermilion Index } & \multicolumn{2}{|c|}{ Total } & \multirow{2}{*}{ P-value } \\
\hline & $\mathbf{N}$ & $\%$ & $\mathbf{N}$ & $\%$ & $\mathbf{N}$ & $\%$ & $\mathbf{N}$ & $\%$ & \\
\hline Quadrangular & 3 & 50.0 & 3 & 50.0 & - & - & 6 & 100.0 & \multirow{3}{*}{$\begin{array}{c}\mathrm{KW}=5.37 \\
* \boldsymbol{P}=\mathbf{0 . 0 5 1}\end{array}$} \\
\hline Triangular & 15 & 71.4 & 6 & 28.6 & - & - & 21 & 100.0 & \\
\hline One point & 4 & 100.0 & & - & - & - & 4 & 100.0 & \\
\hline Attachments & 14 & 87.5 & 2 & 12.5 & - & - & 16 & 100.0 & \\
\hline Total & 70 & 76.9 & 19 & 20.9 & 2 & 2.2 & 91 & 100.0 & \\
\hline
\end{tabular}

Table 9. Teeth mobility (TM) index according to denture support.

\begin{tabular}{|c|c|c|c|c|c|c|c|c|c|c|c|c|c|}
\hline \multirow{3}{*}{ Denture support } & \multicolumn{10}{|c|}{ Teeth Mobility } & \multirow{2}{*}{\multicolumn{2}{|c|}{ Total }} & \multirow{3}{*}{ P-value } \\
\hline & \multicolumn{2}{|c|}{$\mathbf{0}$} & \multicolumn{2}{|c|}{1} & \multicolumn{2}{|c|}{2} & \multicolumn{2}{|c|}{3} & \multicolumn{2}{|c|}{4} & & & \\
\hline & $\mathbf{N}$ & $\%$ & $\mathbf{N}$ & $\%$ & $\mathbf{N}$ & $\%$ & $\mathbf{N}$ & $\%$ & $\mathbf{N}$ & $\%$ & $\mathbf{N}$ & $\%$ & \\
\hline Quadrangular & 3 & 50.0 & 3 & 50.0 & - & - & - & - & - & - & 6 & 100.0 & \\
\hline Triangular & 13 & 61.9 & 7 & 33.3 & 1 & 4.8 & - & - & - & - & 21 & 100.0 & $\mathrm{KW}=8.94$ \\
\hline One point & - & - & 3 & 75.0 & 1 & 25.0 & - & - & - & - & 4 & 100.0 & \\
\hline Attachments & 13 & 81.3 & 3 & - & - & - & - & - & - & - & 16 & 100.0 & \\
\hline Total & 52 & 57.1 & 28 & 30.8 & 6 & 6.6 & 2 & 2.2 & 3 & 3.3 & 91 & 100.0 & \\
\hline
\end{tabular}

Table 10. Bleeding on probing (BOP) index according to RPD design.

\begin{tabular}{|c|c|c|c|c|c|c|c|}
\hline \multirow[b]{2}{*}{ RPD design } & \multicolumn{4}{|c|}{ BOP Index } & \multirow{2}{*}{\multicolumn{2}{|c|}{ Total }} & \multirow[b]{2}{*}{ P-value } \\
\hline & \multicolumn{2}{|c|}{ Yes } & \multicolumn{2}{|c|}{ No } & & & \\
\hline Clasps & 39 & 52.0 & 36 & 48.0 & 75 & 100.0 & $X^{2}=0.002$ \\
\hline Attachments & 9 & 56.3 & 7 & 43.8 & 16 & 100.0 & $P=0.963$ \\
\hline
\end{tabular}


Table 11. Periodontal probing depth (PD) according to RPD design.

\begin{tabular}{|c|c|c|c|c|c|c|c|c|c|c|c|}
\hline \multirow{3}{*}{ RPD design } & \multicolumn{8}{|c|}{ Periodontal probing depth } & \multirow{2}{*}{\multicolumn{2}{|c|}{ Total }} & \multirow{3}{*}{ P-value } \\
\hline & \multicolumn{2}{|c|}{$0=<2 \mathrm{~mm}$} & \multicolumn{2}{|c|}{$1=2-3 \mathrm{~mm}$} & \multicolumn{2}{|c|}{$2=3-4.9 \mathrm{~mm}$} & \multicolumn{2}{|c|}{$3=5+\mathbf{m m}$} & & & \\
\hline & $\mathbf{N}$ & $\%$ & $\mathbf{N}$ & $\%$ & $\mathbf{N}$ & $\%$ & $\mathbf{N}$ & $\%$ & $\mathbf{N}$ & $\%$ & \\
\hline Clasps & 33 & 44.0 & 26 & 34.7 & 15 & 20.0 & 1 & 1.3 & 75 & 100.0 & $\mathrm{U}^{\prime}=13.0$ \\
\hline Attachments & 8 & 50.0 & 5 & 31.3 & 3 & 18.8 & - & - & 16 & 100.0 & $\mathrm{P}=0.200$ \\
\hline Total & 41 & 45.1 & 31 & 34.1 & 18 & 19.8 & 1 & 1.1 & 91 & 100.0 & \\
\hline
\end{tabular}

Table 12. Plaque Index (PI) based on Silness and Löe according to RPD design.

\begin{tabular}{|c|c|c|c|c|c|c|c|c|c|c|c|}
\hline \multirow{3}{*}{ RPD design } & \multicolumn{8}{|c|}{ Sillnes / Löe Index } & \multirow{2}{*}{\multicolumn{2}{|c|}{ Total }} & \multirow{3}{*}{ P-value } \\
\hline & \multicolumn{2}{|c|}{0} & \multicolumn{2}{|c|}{1} & \multicolumn{2}{|c|}{2} & \multicolumn{2}{|c|}{3} & & & \\
\hline & $\mathbf{N}$ & $\%$ & $\mathbf{N}$ & $\%$ & $\mathbf{N}$ & $\%$ & $\mathbf{N}$ & $\%$ & $\mathbf{N}$ & $\%$ & \\
\hline Clasps & 17 & 68.0 & 46 & 85.2 & 10 & 100.0 & 2 & 100.0 & 75 & 82.4 & $U^{\prime}=14.0$ \\
\hline Attachments & 8 & 32.0 & 8 & 14.8 & - & - & - & - & 16 & 17.6 & $\mathrm{P}=0.114$ \\
\hline Total & 25 & 100.0 & 54 & 100.0 & 10 & 100.0 & 2 & 100.0 & 91 & 100.0 & \\
\hline
\end{tabular}

Table 13. Calculus Index (CI) based on Green-Vermilion according to RPD design.

\begin{tabular}{|c|c|c|c|c|c|c|c|c|c|}
\hline \multirow{3}{*}{ RPD design } & \multicolumn{6}{|c|}{ Green Vermilion Index } & \multirow{2}{*}{\multicolumn{2}{|c|}{ Total }} & \multirow{3}{*}{ P-value } \\
\hline & \multicolumn{2}{|c|}{$\mathbf{0}$} & \multicolumn{2}{|c|}{1} & \multicolumn{2}{|c|}{2} & & & \\
\hline & $\mathbf{N}$ & $\%$ & $\mathbf{N}$ & $\%$ & $\mathbf{N}$ & $\%$ & $\mathbf{N}$ & $\%$ & \\
\hline Clasps & 56 & 74.7 & 17 & 22.7 & 2 & 2.7 & 75 & 100.0 & \multirow{2}{*}{$P=0.344$} \\
\hline Attachments & 14 & 87.5 & 2 & 12.5 & - & - & 16 & 100.0 & \\
\hline Total & 70 & 76.9 & 20 & 22.0 & 2 & 2.2 & 91 & 100.0 & \\
\hline
\end{tabular}

Table 14. Teeth mobility (TM) index according to RPD design.

\begin{tabular}{|c|c|c|c|c|c|c|c|c|c|c|c|c|c|}
\hline \multirow{3}{*}{ RPD design } & \multicolumn{10}{|c|}{ Teeth Mobility } & \multirow{2}{*}{\multicolumn{2}{|c|}{ Total }} & \multirow{3}{*}{ P-value } \\
\hline & \multicolumn{2}{|c|}{$\mathbf{0}$} & \multicolumn{2}{|c|}{1} & \multicolumn{2}{|c|}{2} & \multicolumn{2}{|c|}{3} & \multicolumn{2}{|c|}{4} & & & \\
\hline & $\mathbf{N}$ & $\%$ & $\mathbf{N}$ & $\%$ & $\mathbf{N}$ & $\%$ & $\mathbf{N}$ & $\%$ & $\mathbf{N}$ & $\%$ & $\mathbf{N}$ & $\%$ & \\
\hline Clasps & 39 & 52.0 & 25 & 33.3 & 6 & 8.0 & 2 & 2.7 & 3 & 4.0 & 75 & 100.0 & $U^{\prime}=32.0$ \\
\hline Attachments & 13 & 81.3 & 3 & 18.8 & - & - & - & - & - & - & 16 & 100.0 & ${ }^{*} P=0.058$ \\
\hline Total & 52 & 57.1 & 28 & 30.8 & 6 & 6.6 & 2 & 2.2 & 3 & 3.3 & 91 & 100.0 & \\
\hline
\end{tabular}

Table 15. Gingival recession (GR) index according to RPD design.

\begin{tabular}{|c|c|c|c|c|c|c|c|}
\hline \multirow{3}{*}{ RPD design } & \multicolumn{4}{|c|}{ Gingival Recession } & \multirow{2}{*}{\multicolumn{2}{|c|}{ Total }} & \multirow{3}{*}{ P-value } \\
\hline & \multicolumn{2}{|c|}{ Yes } & \multicolumn{2}{|c|}{ No } & & & \\
\hline & $\mathbf{N}$ & $\%$ & $\mathbf{N}$ & $\%$ & $\mathbf{N}$ & $\%$ & \\
\hline Clasps & 60 & 80.0 & 15 & 20.0 & 75 & 100.0 & $X^{2}=9.91$ \\
\hline Attachments & 6 & 37.5 & 10 & 62.5 & 16 & 100.0 & $* P=0.0016$ \\
\hline Total & 66 & 72.5 & 25 & 27.5 & 91 & 100.0 & \\
\hline
\end{tabular}


Depending on the type of denture support and designs of RPDs with clasp ore with attachment during our study we founded minor differences that occur on the periodontal abutment teeth. Therefore, the values of all periodontal parameter as BOP, PD, PI, CI, GR, TM were higher between dental support of RPD, there were no significant difference between them, because of the small number of patients with quadrangular and one point denture support of RPD.

According to authors, an ideal design for RPD was minimal stress in abutment teeth and alveolar ridges, so correct design of the RPD does not cause any damage to the abutment teeth depending of the type of retention [28-30]. The literature suggests that clasp retained design produce less torque on abutment teeth than attachment designs [31, 32]. Addy M, Bates JF., concluded that the denture design should be as simple as possible; covering only the essential hard and soft tissues and a higher level of oral hygiene is needed for RPD patients [11].

Depending on the design of RPD although no significant differences was found in BOP, PD, PI, CI, TM index in abutment teeth; however the values of all periodontal parameter as BOP, PD, PI, CI, TM were higher in patients with RPD's framework with claps retained compared with RPD's with attachment. Except GR-index according to denture design $\mathrm{p}<0.01$ confirmed statistically significant difference in RPD with clasp. This is because bacterial plaque retained in regions covered by the dentures and below to clasp arms in abutment teeth and the most patients presented with gingival recession after 4-5 years. This finding is in agreement with the results of authors Wright PS, Hellyer PH., to the fact that gingival recession appears to increase gradually with age [33]. Because of the small number of patients with RPD with attachment the difference has not been significant and the results must be judged carefully. Therefore the existing results are inconclusive and sometimes contradictory.

Most of the studies have compared the periodontal parameter of abutment and non - abutment teeth that differ from our research. Significant differences $(p<0.01)$ were noted for PI, CI, GI, PD, TM, and GR between abutment and non-abutment teeth, with abutment teeth showing more disease, for different periods ranging from 1 to 10 years [8]. Yeung et al. analyzed a total of 87 patients 5-6 years after placement cobalt-chromium RPD's wearers and concluded there was a high prevalence of gingivitis, plaque, and gingival recession, especially in dento-gingival surfaces in close proximity (within $3 \mathrm{~mm}$ ) to the dentures [15]. Furthermore, according to the author do Amaral BA., plaque index values significantly increased after one year of RPD's wearing in abutment teeth, comparing with non-abutment teeth. It was also confirmed that PD and GI mean values increased from the initial assessment to 1 year of RPD's [34].

A further limitation of this study could be explained due to short period of this study, unlike the other studies they examined the teeth 5 to 10 years after wearing the RPDs. The potential changes in the oral cavity caused by the denture must be considered during planning design of RPD.

The results indicate that patients with RPDs wearers should be motivated for extra adequate oral hygiene instructions. In order to eliminate the periodontal damages caused by RPDs regular recall system is strongly recommended
[35]. Some clinical studies have shown that after the regular examinations, re-instructions and the patient's re-motivation oral hygiene maintenance, RPDs will not cause changes in periodontal abutment teeth [36, 37].

The need for partially edentulous care will be increasing. Patient use of RPDs has been high in the past and is expected to continue in the future. Some patients who are given the choice between an implant-supported prosthesis and a removable partial denture are not able to pursue implant care. This contributes to higher use of removable partial dentures [38].

\section{CONCLUSION}

RPD with clasp increased levels of gingival inflammation in regions covered by the dentures and below the clasp arms in abutment teeth. With carefully planned prosthetic treatment, with suitable design and adequate maintenance of the oral and denture hygiene we can prevent the periodontal diseases of abutment teeth. Aspect of the design of RPD includes not only static-dynamic but also biological principle for the patients, affecting longevity and success of treatment. Regular recall of appointments plays an important role in preventing changes of abutment tooth.

\section{LIST OF ABBREVIATIONS}

$\mathrm{RPD}=$ Removable partial dentures
$\mathrm{PI}=$ Plaque index
$\mathrm{CI}=$ Calculus index
$\mathrm{BOP}=$ Bleeding on probing
$\mathrm{PD}=$ Probing depth
$\mathrm{GR}=$ Gingival recession
$\mathrm{TM}=$ Tooth mobility

\section{CONFLICT OF INTEREST}

The authors confirm that this article content has no conflict of interest.

\section{ACKNOWLEDGEMENTS}

LD collected all the data from the patients, participated in the writing of the manuscript and in the statistical analysis. EA and ZLK were principal investigators and participated in all phases of the manuscript and advised how to conduct the statistical analysis. KSH has been supervisor of the project. All authors read and approved the final manuscript and participated in the bibliography review.

The authors acknowledge all the patients of the University Dentistry Clinical Center, Pristina, Kosova that have facilitated in this study.

\section{REFERENCES}

[1] Wagner B, Kern M. Clinical evaluation of removable partial dentures 10 yeras after insertion: success rates, hygienic problems, and technical failures. Clin Oral Invest 2000; 4: 74-80.

[2] McGivney GP, Castleberry DJ. McCracken's: removable partial prosthodontics, $8^{\text {th }}$ ed. St Louis: Mosby 1989. 
[3] Marxkors R. The partial denture with metal framework. Bremen, Germany: BEGO, Bremer Goldschlägarei Wilhelm Herbst 1984.

[4] Bergman B. Periodontal reactions related to removable partial dentures. Literature review. J Prosthet Dent 1987; 58: 454-457.

[5] Vacaru R, Podariu AC, Jumanca D, Galuscan A, Muntean R. Periodontal-restorative interrelationships. Oral Health Dent Med Bas Sci 2003; 3: 12-5.

[6] Davenport JC, Basker RM, Heath JR, Ralph JB, Glantz P-O. A clinical guide to removable partial dentures. The removable partial denture equation. Br Dent J 2000; 189: 414-24.

[7] Sesma N, Lagana DC, Morimoto S, Gil C. Effect of denture surface glazing on denture plaque formation. Braz Dent J 2005; 16:129-34.

[8] Davenport JC, Basker RM, Heath JR, Ralph JB, Glantz P-O, Hammond P. A clinical guide to removable partial dentures. Connectors. Br Dent J 2001; 190: 184-91.

[9] Zlatarić DK, Čelebić A, Valentić-Peruzović M. The effect of removable partial dentures on periodontal health of abutment and non-abutment teeth. J Periodontal 2002; 73: 137-144.

[10] Körber E, Lehmann K, Pangidis C. Kontrolluntersuchungen an parodontal und paradontal-gingival gelagerten. Teilprothesen. Deutsche Zahnärztliche Zeitschrift 1975; 30: 77-84.

[11] Addy M, Bates JF. Plaque accumulation following the wearing of different types of removable partial dentures. J Oral Rehabil 1979; 6: 111-7.

[12] Mojon P, Rentsch A, Butz-Jorgensen E. Relationship between prosthodontic status, caries and periodontal disease in geriatric population. Int J Prosthodent 1995; 8: 564-71.

[13] de Baat C. Elderly people and removable partial dentures. Ned Tijdschr Tandheelkd 2009; 116: 665-8.

[14] Bergman B, Hugoson A, Olsson CO. Caries, periodontal and prosthetic findings in patients with removable partial dentures: a ten-year longitudinal study. J Prosthet Dent 1982; 48: 506-14.

[15] Yeung AL, Lo EC, Chow TW, Clark RK. Oral health status pf patients 5 to 6 years after placement of cobalt-chromium removable partial dentures. J Oral Rehabil 2000; 27: 183-9.

[16] Preshaw PM, Walls AW, Jakubovics NS, Moynihan PJ, Jepson NJ, Loewy Z. Association of removable partial denture use with oral and systemic health. J Dent 2011; 39: 711-9.

[17] Rodan R, Al-Jabrah O, Ajarmah M. Adverse effects of removable partial dentures on periodontal status and oral health of partially edentulous patients. JRMS 2012; 19: 53-8.

[18] Rissin L, Feldman RS, Kapur KK, Chauncey HH. Six-year report of the periodontal health of fixed and removable partial denture in abutment teeth. J Prosthet Dent 1985; 54: 461-7.

[19] Yap UJ, Ong G. Periodontal considerations on restorative dentistry. Part II: Prosthodontic considerations. Dental Update 1995; 22: 136.

[20] Phoenix RD, Cagna DR, Charles F. Stewart's: Clinical Removable Partial Prosthodontics. DeFreest. $4^{\text {th }}$ ed. 2008.
[21] Steffel VL. Planing removable partial dentures. J Prosthet Dent 1962; 12: 524-35.

[22] Silness J, Löe H. Periodontal disease in pregnancy (2) correlation between oral hygiene and periodontal condition. Acta Odont Scand 1964; 22: 121-35.

[23] Greene JC, Vermillion JR. The simplified oral hygiene index. J Am Dent Assoc 1964; 68: 7-13.

[24] Ainamo J, Bay I. Problems and proposals for recording gingivitis and plaque. Int Dental J1975; 25: 229-35.

[25] Mombelli A. Clinical parameters: biological validity and clinical utility. Periodontol 2000 2005; 39: 30-9.

[26] Baker DL, Seymour GJ. The possible pathogenesis of gingival recession. A histological study of induced recession in the rat. J Clin Periodontal 1976; 3: 208-19.

[27] Miller PD Jr. A classification of marginal tissue recession. Int J Perio Rest Dent 1985; 5: 9-13.

[28] Lee HE, Wu JH, Wang CH, et al. Biomechanical analysis of distal extension removable partial dentures with different retainers. J Dent Sci 2008; 3: 133-9.

[29] Kapur KK, Deupree R, Dent RJ, Hasse AL. A randomized clinical trial of two basic removable partial denture designs. Part I: Comparisons of five year success rates and periodontal health. J Prosthet Dent 1994; 72: 268-82.

[30] Bergman B, Hugoson A, Olsson CO. A 25-year longitudinal study of patients treated with removable partial dentures. J Oral Rehabil 1995; 22: 595-9.

[31] Chou T-M, Caputo AA, Moore DJ, Xiao B. Photoelastic analysis and comparison of force-transmission characteristics of intracoronal attachments with clasp distal-extension removable partial dentures. J Prosthet Dent 1989; 62: 313-9.

[32] Chou TM, Eick JD, Moore DJ, Tira DE. Stereophotogrammetric analysis of abutment tooth movement in distal-extension removable partial dentures with intracoronal attachments and clasps. J Prosthet Dent 1991; 66: 343-9.

[33] Wright PS, Hellyer PH. Gingival recession related to removable partial dentures in older patients. Prosthet Dent 1995; 74(6): 602-7.

[34] do Amaral BA, Barreto AO, Gomes Seabra E, et al. A clinical follow-up study of the periodontal conditions of RPD abutment and non-abutment teeth. J Oral Rehabil 2010; 37: 545-52.

[35] Kern M, Wagner B. Periodontal findings in patients 10 years after insertion of removable partial dentures. J Oral Rehab 2001; 28: 991-7.

[36] Bergman B, Ericson A, Molin M. Long-term clinical results after treatment with conical crown-retained dentures. Int J Prosthodont 1996; 9: 533-8.

[37] Qudah SA, Nassrawin N. Effect of removable partial denture on periodontal health. JRMS 2004; 11: 17-19.

[38] McGivney GP, Castleberry DJ. McCracken's removable prosthodontics. $9^{\text {th }}$ ed. St Louis: Mosby 1995. 